\title{
Local Seismic Cultures: The use of timber frame structures in the South of Portugal
}

\author{
Javier Ortega $^{1, a}$, Graça Vasconcelos ${ }^{1, b}$, Hugo Rodrigues ${ }^{2, c}$ and \\ Mariana Correia ${ }^{3, d}$ \\ ${ }^{1}$ ISISE, Departamento de Engenharia Civil, Universidade do Minho, \\ Campus de Azurem, 4800-058, Guimarães, Portugal \\ ${ }^{2}$ RISCO, Escola Superior de Tecnologia e Gestão, Instituto Politécnico de Leiria, \\ Campus 2, 2411-901, Leiria, Portugal \\ ${ }^{3} \mathrm{Cl}$-ESG Research Centre, Escola Superior Gallaecia, \\ Largo das Oliveiras, 4920-275, Vila Nova de Cerveira, Portugal \\ ajavier.ortega@civil.uminho.pt, ${ }^{b}$ graca@civil.uminho.pt, ${ }^{c}$ hugo.f.rodrigues@ipleiria.pt, \\ dmarianacorreia@esg.pt
}

Keywords: Pombalino construction system, Vila Real de Santo António, Local Seismic Culture, Seismic vulnerability, structural alterations.

\section{Introduction}

Local Seismic Cultures and traditional earthquake resistant constructions and techniques arise in seismic prone regions as a reaction to earthquakes. People continuously exposed to seismic hazard eventually had to learn how to protect themselves and developed preventive measures for earthquake mitigation. These construction efforts made by local populations gave rise to the development of what was defined by Ferrigni [1] as Local Seismic Culture.

In Portugal, there is a particular well-known and widely studied type of timber frame construction that can be highlighted as the most representative example of Portuguese Seismic Culture: the Pombalino construction system [2,3]. This system was devised by the government and its use for the complex reconstruction process carried out in Lisbon after the 1755 earthquake was mandatory. It can be considered as the first technical regulation regarding seismic resistance. Furthermore, local communities adopted this constructive system as a model of earthquake resistant construction and its use widely spread around the country, eventually becoming endemic of the vernacular way of building of the country.

Given the fact that using timber frame structures has proven to improve the seismic behavior of vernacular architecture, as has been reported in past earthquakes in many countries [4-7], its preservation as a traditional earthquake resistant practice is important. This paper firstly intends to evaluate whether the use of timber frames as a traditional seismic resistant technique for vernacular architecture in the South of Portugal, traditionally a seismic region, is still active. Secondly, the city of Vila Real de Santo António was selected as a case study because it also followed a Pombaline development contemporary to the reconstruction of Lisbon. The plan included the provision of timber frame partition walls for some of the buildings and, thus, an overview of the type of constructions originally conceived is provided. Finally, the alterations done in the original constructions and the current state of the city center are described and the effect of these changes on the seismic vulnerability of the city is discussed. 


\section{Structural timber frames and Local Seismic Cultures}

Structural timber frames are a very common vernacular practice that can be observed in many seismic prone areas. Traditionally, the use of timber reinforcement elements embedded within the rubble, mud bricks or ashlar masonry walls consists, in many cases, of just a few vertical or horizontal timber elements inserted within the walls or a rough timber grid of horizontal timber trunks or tree branches lying longitudinally and transversally at different levels of the wall. However, in some other cases, these timber reinforcements were sophistically arranged constituting the main load-bearing element of the building and a proper structural timber frame. The use of timber frames filled with masonry is clearly a strengthening method applied because of the excellent tensile properties of the timber and also because the timber elements constitute successful slip planes and both vertical and horizontal shock absorbers, helping to dissipate much more energy. This vertical, horizontal and, in many cases, diagonal reinforcement, also improves the connections between the different structural elements among themselves, tying the building and enhancing its 'box-behavior'. Furthermore, it can restrain the out-of-plane bending and in-plane shear effects because, by confining portion of the walls, it enhances the masonry compressive strength, its shear strength and its deformability properties [8].

Different types of structural timber frames can be observed as seismic reinforcement for vernacular constructions in many countries, such as Greece [8], Turkey, where is known as hatil [9], Northern Pakistan, where is known as cator and cribbage [5], or in Kashmir, where there are two main types known as taq and dhajji-dewari [6]. Also in Central and South America, there are timber frame constructions used since Pre-Hispanic times in rural houses, known as bahareque in Colombia, Ecuador and El Salvador, quincha in Peru and taquezal in Nicaragua.

The Portuguese case. There are several particular cases throughout history in which devastating earthquakes induced the development of building regulations for the reconstruction of the city through a post-earthquake concerted response that involved the government of that time. Generally, these regulations intended to prevent future losses of life and property by providing rules concerning urban planning and architectural practices, establishing height restrictions, fireproofing systems and sometimes even creating new seismic resistant structural systems. This happened in Portugal, after the most destructive earthquake in the history of the country in 1755, which destroyed large areas of Lisbon, including the downtown.

A complex reconstruction process was organized by the Marquis of Pombal and introduced new urban, architectural and structural concepts. It was strictly enforced and the constructions built according to them are known as Pombalino buildings. The most relevant seismic resistant provision was the inclusion of a three-dimensional braced timber frame structure named gaiola pombalina as the internal structure of the building. The gaiola is a resistant and flexible cage, whose walls are composed by horizontal, vertical and diagonal timber elements with different geometries, usually filled with rubble or brick masonry and plastered. These walls are known as frontal walls. The timber elements are connected using traditional solutions, such as dovetail or mortise and tenon, and are sometimes reinforced with nails or metal elements. The external walls are made of stone masonry and the frontal walls, act as the shear walls of the building, enabling it to resist horizontal loads by dissipating substantial amounts of energy and by providing a bracing function, avoiding the premature out-of-plane collapse of the exterior masonry walls. A minimal timber skeleton can be also present in the inner face of the masonry walls, facilitating their connection with the floors and the inner timber frame shear walls.

\section{Timber frame structures in the South of Portugal}

As previously commented, the Pombalino structure developed in Lisbon was also exported to surrounding villages and cities in Portugal where it became part of the vernacular way of building, as a clear evidence of the local builders' seismic concern, who acknowledged that the system actually improved the seismic behavior of their constructions. As a consequence, nowadays, frontal walls can be identified in many vernacular constructions scattered around the 
country, including the South of Portugal (Fig. 1). A relevant example is the case of Benavente (Fig. 1a), a city in the South of Lisbon, where a simplified version of this seismic resistant construction system was chosen for the reconstruction works of the city after the 1909 devastating earthquake, based on the Lisbon experience, and all the rebuilt districts of the town present buildings with a timber skeleton and stone masonry or adobe infill [10].

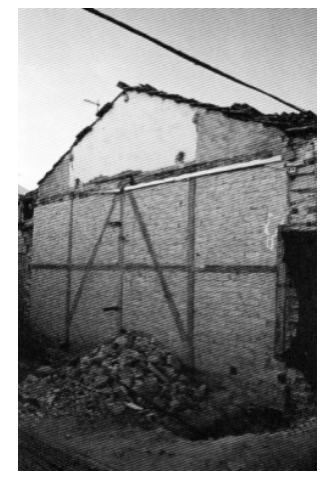

a

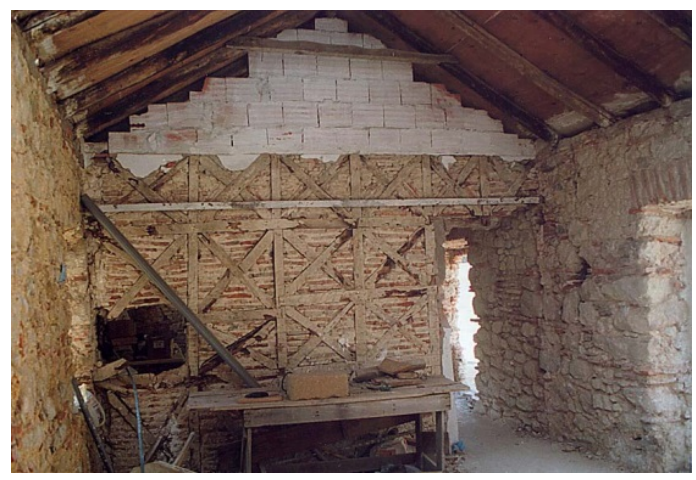

b

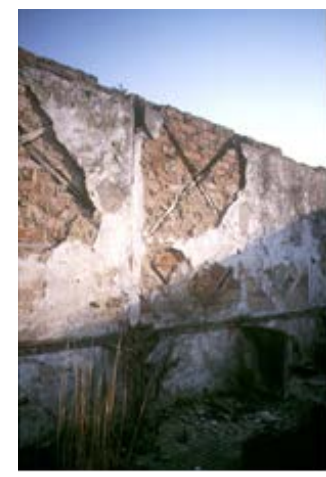

C

Fig. 1. Examples of frontal walls in Portuguese vernacular architecture: (a) Benavente [10]; (b) Alcácer do Sal [11]; and (c) Samora Correia [11].

Nevertheless, the use of this technique has been gradually abandoned. Since there is a close correlation between the earthquake frequency and the development of seismic resistant building practices, when earthquakes are sparse and there are large periods of time without seismic events, larger than an average generation life time, the function of different techniques implemented after an earthquake are forgotten and ultimately abandoned. This adoption of changes in behavioral patterns due to a loss of collective memory of past events eventually leads to the abandonment and erosion of Local Seismic Cultures (Fig. 2a).

The loss of seismic awareness inevitably means an increase in the seismic vulnerability of communities. An illustrative example of this phenomenon took place in Lisbon, where the seismic resistant practices used in the Pombalino buildings were progressively abandoned and a new typology appeared: the gaioleiro buildings. This new typology consisted of four or five stories high stone masonry buildings that respected the Pombalino buildings formal characteristics but had a worse construction quality and neglected the initially devised seismic resistant solutions, such as the structural timber frame, worsening their seismic behavior and increasing their vulnerability [13]. Nonetheless, similar cases occurred in other cities of the country, such as Lagos, in the Algarve region. This city was also very much affected by the 1755 earthquake and reconstruction works introduced structural solutions aiming at improving the seismic behavior of the buildings, such as frontal walls [14]. However, the use of those constructive solutions was eventually abandoned, as people lost awareness of the seismic risk and nowadays only few remains of this seismic culture can be observed in the city (Fig. 2b).
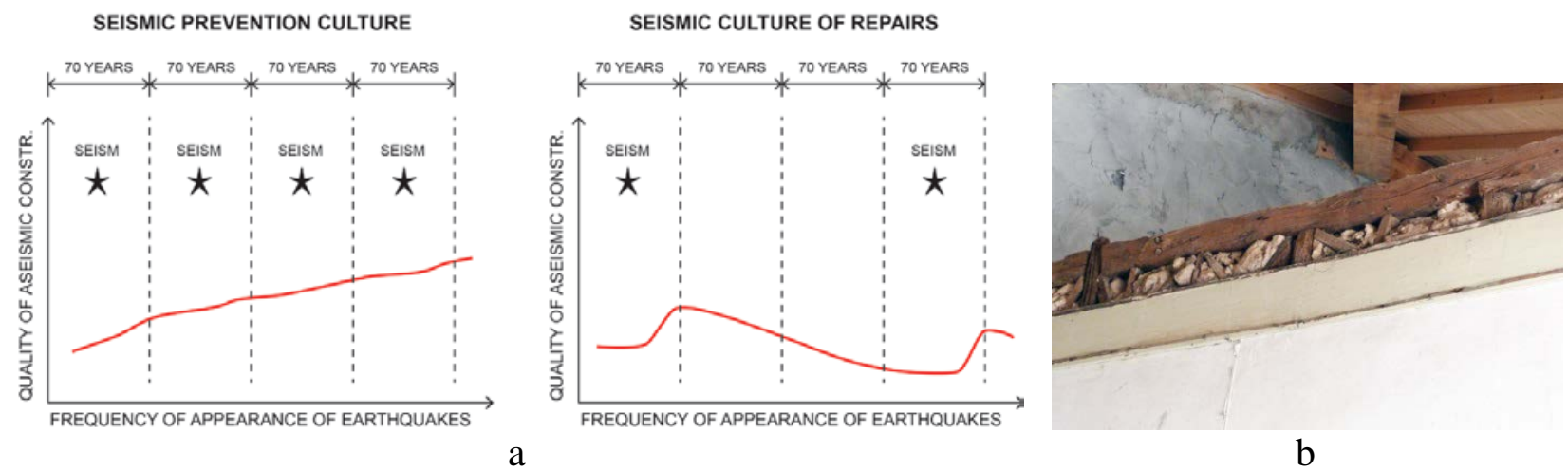
a

Fig. 2. (a) Evolution of the quality of aseismic construction in relation with the earthquake frequency (adapted from [12]); (b) Remaining hidden frontal wall in Lagos. 


\section{Vila Real de Santo António}

The reconstruction of Lisbon was not an isolated event. Vila Real de Santo António is located in the region of Algarve, the southernmost area of Portugal, which has a significant seismicity. It was much affected by the 1755 earthquake and was practically abandoned at the time. However, the Marquis of Pombal considered that this region had a considerable economic potential and enacted an official recovery program during the 1760s and 1770s that included the setting-up of a completely new planned town. The city was built at the end of the $18^{\text {th }}$ Century, contemporary to Lisbon, and followed similar urban, architectural and construction solutions, including the use of seismic resistant measures, such as the use of the characteristic timber frame frontal walls. The main reason for planning an entire new city was the attempt to boost the Algarve local economy through industrial development [2] but also was created for the control of port transactions and as a display of political power, because of its strategic position, at the extreme South of the Algarve facing the Spanish border [15].

The new Pombaline city plan was formed by a rectangular area with one of the long sides placed along the Guadiana River, facing east, and consisted of a grid of seven by six urban blocks organized around a big central square (Fig. 3). The whole plan is characterized by its strong regularity, where all the blocks are approximately $53 \mathrm{~m}$ long and $22 \mathrm{~m}$ wide, with the exception of the central one, which is slightly longer, approximately $55 \mathrm{~m}$. All the streets are $9 \mathrm{~m}$ wide. There are essentially four distinct architectural types that defined a clear hierarchy at an urban level: (a) buildings in the riverfront, which have two main stories and a third attic floor; (b) buildings in the main square, which also have two main stories; (c) single story dwellings, characterized by their small scale and simplicity; and (d) single story factories and warehouses, which basically consists of a system of masonry arcades perpendicular to the façade walls and organized around a patio. Besides these strongly defined types, there are also some specific unique buildings: the Customs House, the church, and the 'towers'.
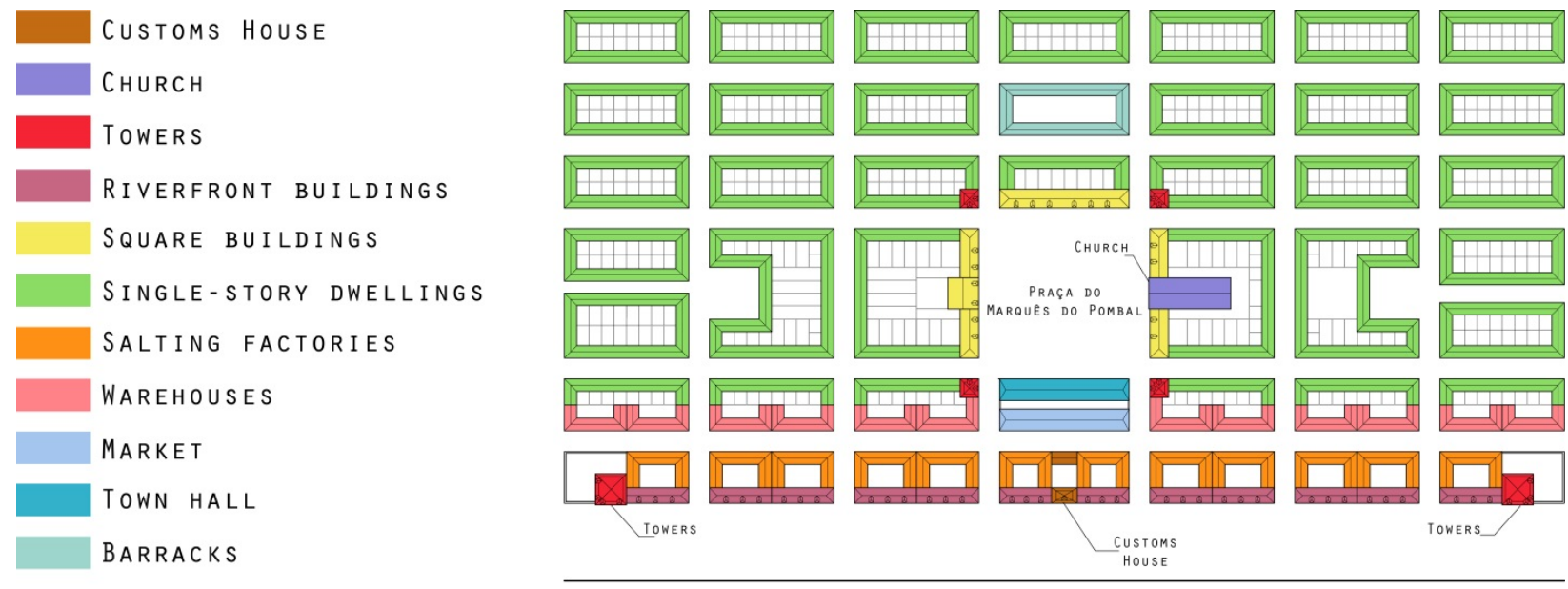

GUADIANA RIVER

Fig. 3. Original plan of Vila Real de Santo António and main building types (adapted from [16]).

In terms of construction and materials, a similar prefabrication process already applied for the Lisbon reconstruction plan, was also applied in the construction of Vila Real. Ashlars used for the quoins or opening frames arrived already cut and worked, ready to be placed, as well as the wooden components, such as doors, windows, beams and floorboards [15]. Stone masonry was used for the load bearing exterior and party walls, which are the main structural resisting elements of all buildings. Timber was used for the roof rafters and trusses, floor beams and timber frame partition walls in upper floors. The roof was simply covered by wooden boards on which ceramic tiles were laid. Some ground floor rooms had vaulted ceilings supporting the first floor as a fire prevention measure, as in Lisbon [2]. Ground floor partition walls were usually built in solid brick masonry. The buildings were plastered with lime and sand and whitewashed. 
Use of frontal walls. With respect to the seismic resistant constructive solutions introduced in the buildings at the time of their construction, the most significant elements were the timber frame structures used as partition walls in the upper floor of the two-story buildings (Fig. 4). They are similar to those used in the Pombaline quarter in Lisbon but, given the low height of the buildings, the use of the whole gaiola seismic resistant construction system developed for the reconstruction of Lisbon, was not necessary. Nevertheless, the timber roof structure and the timber floor structure were connected through these frontal partition walls [15]. These walls consisted of vertical, horizontal and diagonal timber members filled with stone masonry coming from neighboring quarries in the mountains.

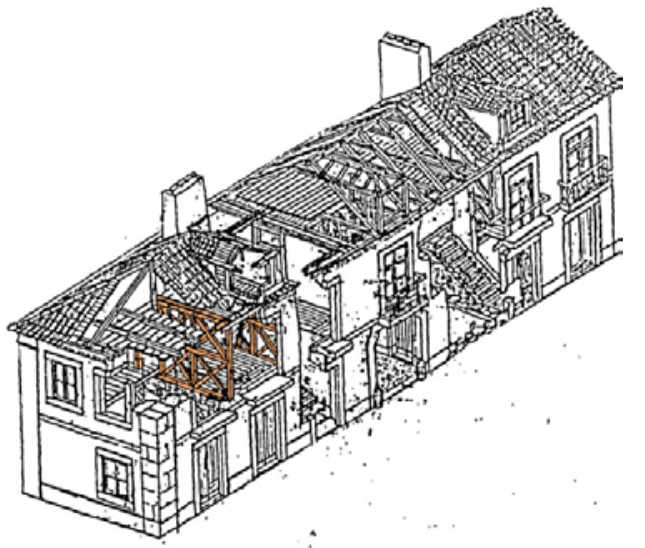

a

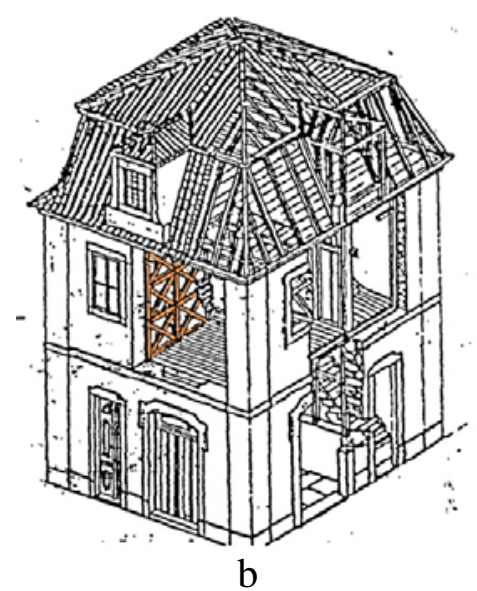

Fig. 4. Use of frontal walls in two-story buildings in Vila Real de Santo António (adapted from [2]): (a) riverfront buildings; (b) one of the 'towers' surrounding the central square.

Some of these timber frame structures were still observed in some of the buildings at the present time. For instance, one of the most representative buildings of the city: the Alfândega or Customs House still present several examples of timber frame partition walls in the upper floors, showing different geometries (Fig. 5a,b). Some of them lack the diagonal timber members (Fig. 5c) but all of them use nails to strengthen the connection between elements. The two 'towers' located in the riverfront also presented frontal walls in the upper floors at the time of the construction, with a stone masonry infill similar to the masonry used for the main load bearing walls (Fig. 5d).

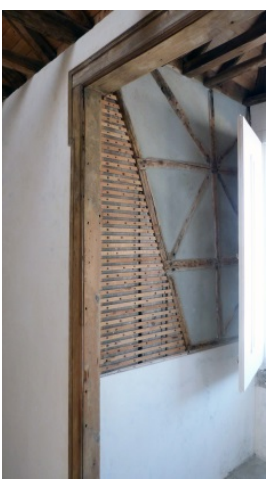

a

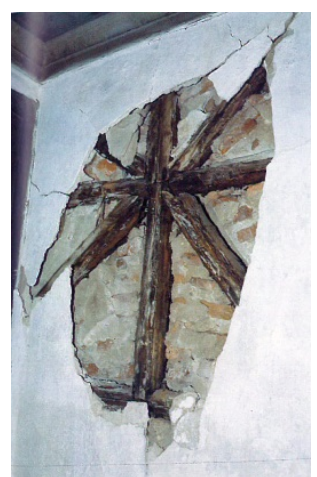

b

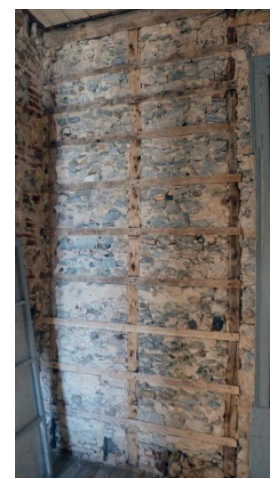

C

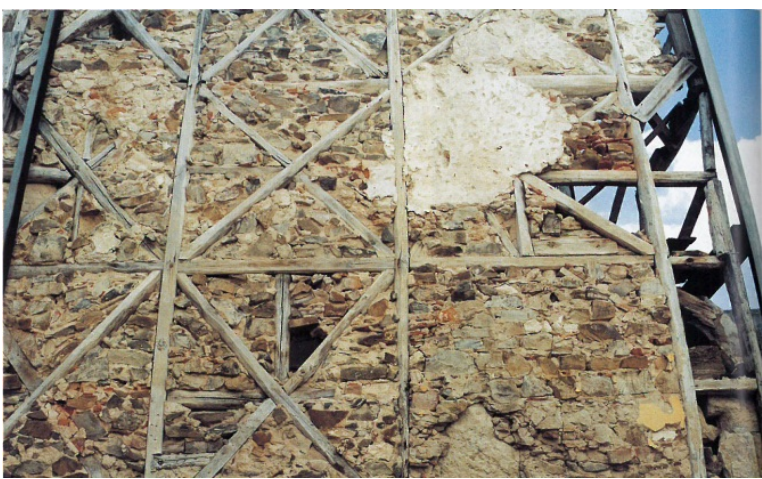

d

Fig. 5. Different type of frontal walls observed in Vila Real de Santo António: (a) Alfândega building; (b) Alfândega building [17]; (c) Alfândega building; (d) South riverfront 'tower' [17].

\section{The current state of the Pombaline core of Vila Real de Santo António}

There has been a transformation process in the city and the works carried out in the Pombaline core have led to an important depravation of the historical built-up fabric. Only very few buildings still possess Pombaline characteristics, such as the original masonry walls or the opening distribution (Fig. 6a). Generally, the transformation process has been characterized by a 
massive occupation of the blocks, leading to an extreme densification of the urban fabric, since patios were continuously occupied by additional constructions. Single story buildings have been systematically exposed to demolitions, substitutions and large modifications, but even the best preserved buildings still show important alterations in relation to their original conception.

The main alterations that can be found in the original constructions involve the addition of new floors, the opening of new windows and doors, the enlargement of the original openings or the substitution of the original roof and floors (Fig. 6b). Most of these alterations are a normal consequence resulting from the changes of use of the buildings and the new needs of the users. However, they are not only detrimental in terms of loss of authenticity of an important architectural and urban heritage. They also jeopardize the safety of the buildings by directly affecting several parameters that are crucial in the seismic response of the building and introduce new sources of vulnerability.
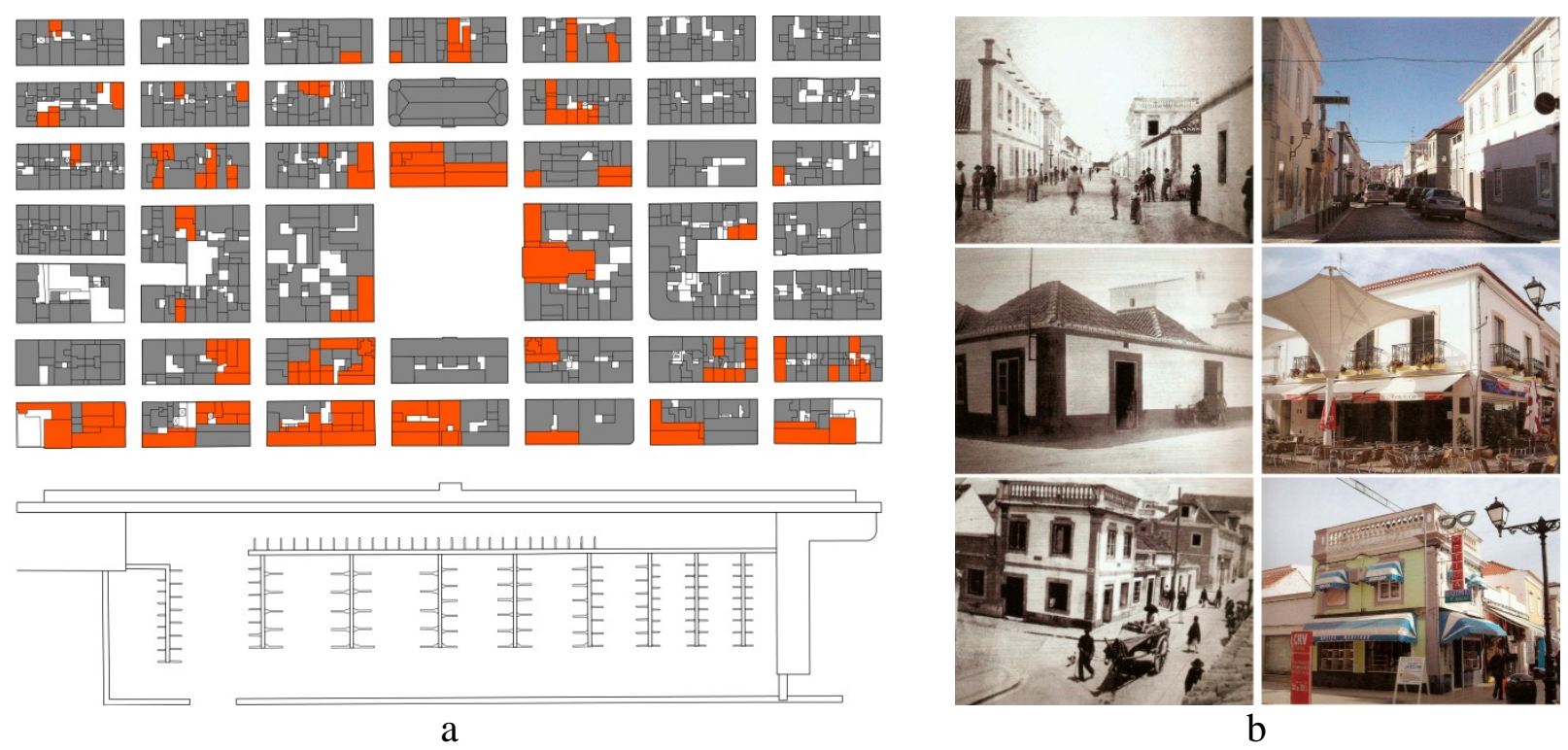

Fig. 6. (a) Current plan of VRSA (highlighted in orange those buildings that still preserve some original characteristics); (b) Common alterations undergone by the original constructions [18].

The substitution and removal of frontal walls. Another systematic alteration that the buildings of Vila Real de Santo António have undergone is the elimination of the original frontal walls, revealing again a loss of seismic awareness by ignoring a distinctly seismic resistant feature of the original buildings. When buildings are reconstructed or rehabilitated, these frontal walls are obliterated or just kept as a vestige, ignoring the actual structural function as a seismic resistant element, which may have contributed to increase the seismic vulnerability of the buildings. This is well exemplified by the rehabilitation of the South riverfront 'tower', where the frontal walls were reconstructed but just as a formal element (Fig. 7).

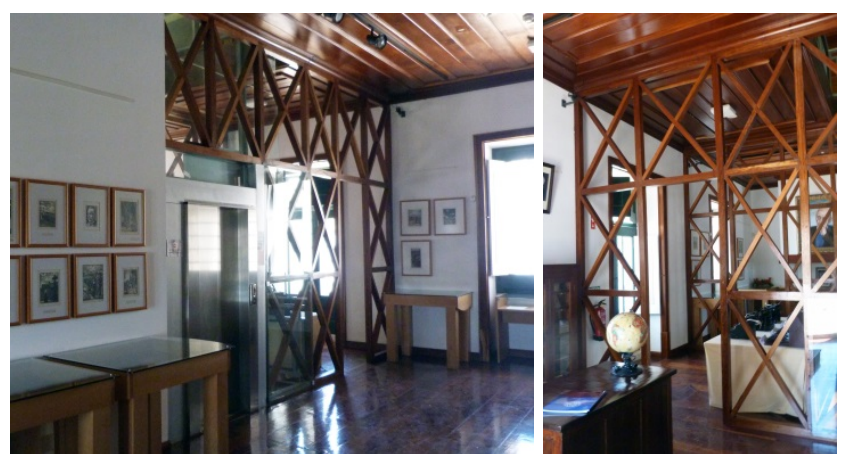

a

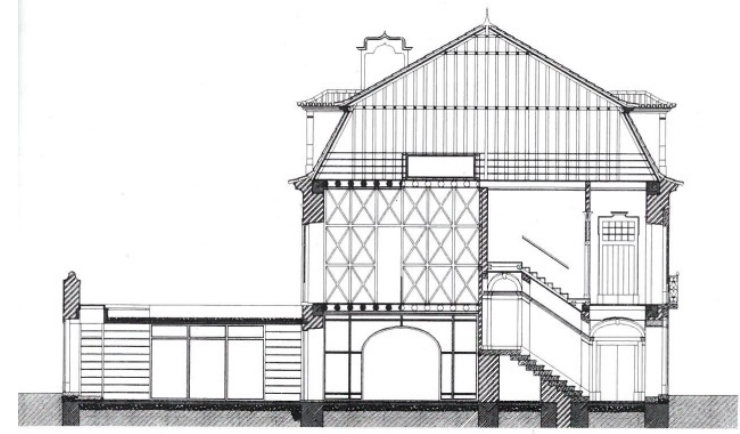

b

Fig. 7. (a) Aesthetic reconstruction of frontal walls in the south riverfront 'tower'; (b) Cross section of the rehabilitation project of the South riverfront 'tower' [17]. 


\section{Conclusions}

Portugal has a moderate seismicity characterized by small events of order of magnitudes smaller than five, but several devastating earthquakes have sporadically struck the country throughout its history. The seismic history is thus distinguished by large periods of time without seismic events and has led to the development of a reactive response behavior in which local communities just respond to earthquakes in the intermediate aftermath of the event. In this way, important measures and seismic resistant construction techniques were devised and implemented after large earthquakes. They were sometimes mandatorily imposed by the government, such as the use of the gaiola construction system and frontal walls. This efficient technique was developed in Lisbon but soon widely spread across the country, as inhabitants understood its potential as a seismic strengthening technique, becoming traditional in many regions. The use of frontal walls in several regions in the South of Portugal has been presented in this paper, as well as its application in a more institutionalized way in the construction of the city of Vila Real de Santo António, a Pombaline development contemporary to the reconstruction of Lisbon.

Nevertheless, these large periods of times without earthquakes have caused those developed seismic resistant solutions to be eventually abandoned and seismic cultures to disappear because of the loss of seismic awareness. Vila Real de Santo António was selected as the main case study because is a good example of this progressive abandonment of traditional strengthening techniques enforced after important seismic events. The seismic concern that arose in the whole country after the 1755 earthquake materialized in several Pombaline developments such as the creation ex novo of Vila Real de Santo António and resulted in an effective urban plan and carefully constructed architecture. However, the deep mischaracterization of the historical city center due to the multiple alterations suffered, led to the oblivion of the developed reinforcement measures, including the use of frontal walls and, as a result, the seismic safety of the buildings may have been compromised. The adequacy and efficiency of these traditional strengthening solutions has been successfully tested over time and, subsequently, they are worthy to be studied. The re-adoption of some of these techniques can help in preserving and retrofitting surviving examples of vernacular architecture without prejudice for its identity.

\section{Acknowledgements}

The authors wish to express their gratitude to the Portuguese Science and Technology Foundation (FCT) for the scholarship granted in the scope of the research project 'SEISMIC-V Vernacular Seismic Culture in Portugal’ (PTDC/ATP-AQI/ 3934/2012).

\section{References}

[1] Ferrigni F., 1990, À la recherché des anomalies qui protégent, Actes des Ateliers Européens de Ravello, 19-27 Novembre, 1987. Ravello: PACT Volcanologie et Archeologie \& Conseil de L'Europe.

[2] Mascarenhas, J., 2004, Sistemas de Construção - V, Livros Horizonte, Lisbon, Portugal.

[3] Cóias, V., 2007, Reabilitação estrutural de edifícios antigos, ARGUMENTUM, GECoRPA, Lisboa, Portugal.

[4] Vintizileou, E., 2011, Timber-reinforced structures in Greece: 2500 BC-1900 AD, in Proceedings of the Institution of Civil Engineers (ICE), Structures and Buildings, 164(SB3), pp. 167-180.

[5] Hughes, R., 2000, Cator and Cribbage Construction of Northern Pakistan, in Proceedings of the International Conference on the Seismic Performance of Traditional Buildings, Istanbul, Turkey. 
[6] Langenbach, R., 2009, Don' Tear it down! Preserving the earthquake resistant vernacular architecture of Kashmir, UNESCO, New Delhi, India.

[7] Gülhan, D., Güney, I.Ö., 2000, The Behaviour of Traditional Building Systems Against Earthquake and its Comparison to Reinforced Concrete Frame Systems; Experiences of Marmara Earthquake Damage Assessment Studies in Kocaeli and Sakarya, in Proceedings of the International Conference on the Seismic Performance of Traditional Buildings, Istanbul, Turkey.

[8] Vintizileou, E., 2008, Effect of Timber Ties on the Behavior of Historic Masonry, Journal of Structural Engineering, 134(6), pp. 961-972.

[9] Langenbach, R., 2007, From “Opus Craticium” to the "Chicago Frame”: EarthquakeResistant Traditional Construction, International Journal of Architectural Heritage, 1(1), pp. 29-59.

[10] Vieira, R.S., 2009, Do Terramoto de 23 de Abril de 1909 à reconstrução da Vila de Benavente. Um processo de reformulação e expansão urbana, Câmara Municipal de Benavente, Benavente, Portugal.

[11] Correia, M., Merten, J., 2001, Preliminary Report of the Local Seismic Culture in Portugal, in Taversism project - Atlas of Local Seismic Culture, EUCCH, Ravello, Italy.

[12] Ferrigni, F., Helly, B., Mauro, A., Mendes Victor, L., Pierotti, P., Rideaud, A., Teves Costa, P., 2005, Ancient Buildings and Earthquakes. The Local Seismic Culture approach: principles, methods, potentialities, Centro Universitario Europeo per i Beni Culturali, Edipuglia srl, Ravello, Italy.

[13] Mendes, N., Lourenço, P.B., 2010, Seismic assessment of masonry “Gaioleiro” buildings in Lisbon, Portugal, Journal of Earthquake Engineering, 14, pp. 80-101.

[14] Paula, R.M., 1992, Lagos, Evolução Urbana e Património, Câmara Municipal de Lagos, Lagos, Portugal.

[15] Correia, J., 1997, Vila Real de Santo António. Urbanismo e Poder na Política Pombalina, PhD Thesis, Faculdade de Aquitectura da Universidade do Porto, Portugal.

[16] Rossa, W., 2009, Cidades da razão: Vila Real de Santo António e arredores, Monumentos, 30, pp. 16-31.

[17] Figueiras, R., 1999, Vila Pombalina: Vila Real de Santo António, Câmara Municipal de Vila Real de Santo António, Vila Real de Santo António, Portugal.

[18] Gonçalves, A., 2009, Vila Real de Santo António. Planeamento de pormenor e salvaguarda em desenvolvimento, Monumentos, 30, pp. 40-53. 